\title{
CLINICAL ONSET OF LUPUS ERYTHEMATOSUS IN THE OLDER AGE GROUP
}

\author{
ROSALINE R. JOSEPH, M.D.* and CHRIS J. D. \\ ZARAFONETIS, M.D., F.A.G.S.†
}

Temple University School of Medicine, Philadelphia, Pennsylvania, and The University
of Michigan School of Medicine, Ann Arbor, Michigan

The original concept of systemic lupus erythematosus was that of a rapidly progressive, often fulminant, fatal disease primarily affecting women in the reproductive age group. Subsequent observations, however, have revealed many additional and protean aspects of this disorder.

The purpose of this report is to call attention to the onset of the disease in one specific group in which it is not often suspected, namely, patients in the sixth decade of life or later (1-8). Although the age range for appearance of the disease is from 2 to 73 years, most of the cases (75-84 per cent) occur between the ages of 10 and 40 years, the average age at onset being from 25 to 30 years. Despite the inclusion of patients aged 50 or over in statistical summaries of previously published series, there has been only 1 such patient reported in detail. Knopf and Castor (9) presented the case of a woman in whom, at age 66, joint pains, pleural effusion and thrombocytopenia developed in association with diagnostic findings in a lupus erythematosus cell preparation. At the time of publication, the patient's symptoms were controlled with minimal dosages of prednisone, aspirin and antimalarials.

In the period 1950-1958, 5 patients with systemic lupus erythematosus whose disease became manifest in the sixth decade of life or later, were studied in the Hematology Section of the Department of Medicine at Temple University Medical Center. This incidence suggests a frequency of onset of systemic lupus erythematosus in the older population greater than generally recognized. Analysis of these cases permits certain preliminary observations on the nature of this variable disease in the elderly patient.

\section{CASE REPORTS}

\section{Case 1}

$W . S .$, a 73 -year-old male, was in his usual state of good health until December 1951, at which time he contracted an acute febrile illness, diagnosed as "flu" and treated with penicillin. He was also found to be anemic and was given a series of four weekly injections of liver extract. Following the fourth injection he became severely ill with loss of appetite, ankle swelling, enlargement of the cervical lymph nodes, swelling of the eyelids with purplish discoloration, abdominal pain, sciatica and iritis. His weight at that time was $\mathrm{Pa}$.

* Assistant Professor of Medicine, Temple University School of Medicine, Philadelphia,

Address: Department of Hematology, Temple University Hospital, Broad and Ontario Streets, Philadelphia, Pa., 19140.

$\dagger$ Professor of Medicine and Director, Simpson Memorial Institute, University of Michigan School of Medicine, Ann Arbor, Michigan. 
recorded as 154 pounds, which represented a loss of approximately 16 pounds from his normal level. Admission to another hospital resulted in the discovery of neutropenia and thrombocytopenia in addition to anemia. Megaloblasts were seen in the sternal marrow aspirate and a diagnosis of pernicious anemia was considered. Accordingly vita$\min \mathrm{B}_{12}$ and folic acid were administered, but the hematologic abnormalities remained unchanged. In July 1952, cortisone therapy was started at the suggestion of an ophthalmologic consultant, because of the persistence of iritis. Despite continued treatment with large doses of cortisone (up to $200 \mathrm{mg}$ daily) and antibiotics, the patient remained ill for several months with intermittent fever ranging up to $103-104^{\circ} \mathrm{F}$, joint swelling, and anemia.

In March 1953, he was referred to one of us (C. Z.) for complete evaluation. In addition to the foregoing, he displayed an extensive papular eruption over the arms, legs and back. Orthopnea was marked. His blood pressure was $160 / 85 \mathrm{~mm} \mathrm{Hg}$. Cardiomegaly was present, but there were no murmurs. The liver and spleen were not palpable. There was edema of the scrotum and of the lower extremities. The deep tendon reflexes were reactive and the deep pain sense was retained in the Achilles tendon.

A Rumpel-Leede test gave moderately positive results. The hemoglobin level was $8.9 \mathrm{gm}$ per cent, the leukocyte count 2,500 per cu mm, erythrocyte count 2.78 million per cu mm, reticulocyte count 2.4 per cent, and thrombocyte count 528,000 per cu $\mathrm{mm}$. The blood Wassermann test gave positive results $(2+)$, as did the Mazzini test (1:8 dilution). The spinal fluid Wassermann results were also positive $(4+)$. However, the colloidal gold test reading on the spinal fluid was 0000000000 . On further questioning it was determined that the patient's blood Wassermann reaction had been positive for forty years and he had been adequately treated for lues despite the fact that there was no history of a primary lesion or known exposure. The Treponema pallidum immobilization test on several serum specimens yielded negative results. A lupus erythematosus cell preparation showed 9 L.E. cells among the $\mathbf{5 0 0}$ white blood cells counted. The direct Coombs' test showed no antibodies. The diagnosis was disseminated lupus erythematosus with false positive luetic serologic findings.

Therapy was started with cortisone $(50 \mathrm{mg}$ daily) potassium para-aminobenzoate (Potaba, $12 \mathrm{gm}$ daily) and acetylsalicylic acid. During the next few months the patient experienced several exacerbations of his illness with high fever, arthralgia, and an erythematous skin eruption. A temporary increase in cortisone dosage to 200 to $250 \mathrm{mg}$ daily usually resulted in subsidence of the acute symptoms, but reduction in dosage was invariably followed by recurrence. $\mathrm{K}$ aminobenzoate was continued during this entire period. By October 1953, approximately six months after institution of combined therapy, the patient was symptom-free. The total daily requirement of cortisone was only $50 \mathrm{mg}$, given in fractional doses.

Subsequently the patient's course was one of general good health with occasional flareups characterized by malaise, fever, skin eruption and ankle swelling. These episodes were short-lived and far between, with good response to short-term increases in corticosteroid and salicylate dosages. At the age of 75 he was able to mow his lawn and walk several miles without undue fatigue.

In May 1960, low back pain and constipation developed and grew progressively worse, necessitating admission to Temple University Hospital on May 31, 1960. The hemoglobin level was $11.7 \mathrm{gm}$ per cent, hematocrit 37 per cent, and leukocyte count 3,600 per cu $\mathrm{mm}$, with $57 \%$ segmented neutrophils, $27 \%$ lymphocytes, $4 \%$ monocytes and $6.5 \%$ disintegrated cells. The reticulocyte count was 2.1 per cent, thrombocyte count 390,000 per cu $\mathrm{mm}$, and erythrocyte count 3.7 million per cu $\mathrm{mm}$. A lupus erythematosus cell preparation showed no L. E. cells. The urine was normal. The concentration of blood urea nitrogen was $18 \mathrm{mg}$ per $100 \mathrm{ml}$, serum calcium $9.2 \mathrm{mg}$ per $100 \mathrm{ml}$, serum phosphorus 3.0 mg per $100 \mathrm{ml}$, serum alkaline phosphatase 12.1 K.A. units, acid phosphatase 2.4 units, and total bilirubin $0.57 \mathrm{mg}$ per $100 \mathrm{ml}$. Roentgen examination of the lumbar spine revealed generalized osteoporosis and a mild compression fracture at L2. Gastrointestinal $\mathrm{x}$-ray examination (barium enema) showed nothing abnormal. 
Strict bedrest was instituted, and therapy consisted of cortisone, Potaba, Empirin compound and supportive care. While the patient was in the hospital, substernal chest pain developed. An electrocardiogram showed right bundle-branch block, premature auricular contractions, diffuse myocardial abnormality, and an old diaphragmatic infarct. The course was one of continued weakness and constipation with progressive disorientation. On July 3, 1960, swelling of the left leg was first noted, but there was no heat, redness or tenderness. This swelling persisted until the patient's death on July 12, 1960, at the age of 80 years.

Necropsy revealed multiple, bilateral pulmonary emboli, bronchopneumonia and pulmonary edema. Examination of the pancreas showed primary adenocarcinoma with thrombosis of the pancreatic vein, cystic obstruction of the ducts and chronic pancreatitis. Metastases were present in the local lymph nodes. The kidneys showed moderate membranous glomerulosclerosis (lupus type) with mild focal pyelonephritis and arteriolosclerosis. There was thrombophlebitis in the vessels of the left leg.

Comment: A striking feature of this case is the 40-year history of a positive reaction with serologic Wassermann or Mazzini tests. Repeated treponemal immobilization tests proved this positive serologic reaction to be non-luetic. Such a false positive reaction in tests on the cerebrospinal fluid has not been reported previously. Also of interest is the apparent amelioration of the disease process during combined corticosteroid-K aminobenzoate therapy. During the first two years of clinically evident lupus erythematosus the patient was acutely ill a great deal of the time and large doses of cortisone were required for suboptimal control. With the addition of $\mathrm{K}$ aminobenzoate, prolonged symptom-free intervals over a 7-year period were achieved with lesser amounts of cortisone.

\section{Case 2}

$S . P$., a 58-year-old male, was first seen at Temple University Hospital in 1952, when he was admitted to the medical ward service with a history of pneumonitis accompanied by minimal pleural effusion and mild arthralgia. A lupus erythematosus cell preparation on July 21,1953 showed $27 \mathrm{~L}$. E. cells per 500 leukocytes examined. The patient's symptoms improved with corticosteroid therapy, and when he was discharged he was taking $100 \mathrm{mg}$ of cortisone daily.

He was next seen on July 14,1954 , when he was readmitted in a comatose, febrile state. The history obtained from the family disclosed that the patient had taken his usual dosage of medication until six days before admission, when the dosage had been increased to $300 \mathrm{mg}$ daily because of the sudden onset of fever and chills. Three days later left-sided hemiparesis developed and the patient gradually became more stuporous. On admission there was an obvious left central seventh-nerve palsy and weakness of the left arm and leg. Moist coarse rales were heard at the left lung base.

Laboratory studies: The hemoglobin level was 12.9 gm per cent, hematocrit 43.5 per cent, reticulocyte count 0.6 per cent, platelet count 872,000 per cu mm, and leukocyte count 8,500 per cu mm, with $7 \%$ band neutrophils, $84.5 \%$ segmented neutrophils, $4.5 \%$ lymphocytes, $3 \%$ monocytes and $1 \%$ disintegrated cells. A lupus erythematosus cell preparation showed only $1 \mathrm{~L}$. E. cell per 500 white cells counted. Repeated urinalyses gave negative results except for variable amounts of glycosuria. The fasting blood sugar level was moderately elevated. A chest roentgenogram showed diffuse exudative lesions compatible with acute pulmonary tuberculosis, and the sputum contained acid-fast bacilli.

Treatment with streptomycin (1 gram daily), potassium aminobenzoate (Potaba, 12 grams daily), and intravenous adrenocorticotropic hormone (ACTH) was given in addition to the corticosteroid therapy. The elevated level of blood sugar was readily controlled with small doses of NPH insulin. The patient's cerebrovascular status improved and the 
pulmonary lesions appeared to be responding to therapy. A cautious attempt was made to lower the corticosteroid dosage, and the last dose of ACTH was given on August 24. On August 25, 1954, the leukocyte count was 2,000 per cu mm, with no segmented neutrophils. Examination of the sternal marrow aspirate revealed complete absence of segmented neutrophils and metamyelocytes, but more primitive forms (blasts, progranulocytes, myelocytes) were present in relative abundance. Erythropoiesis was normal. ACTH was re-started on August 27, 1954 and the leukocyte count rapidly returned to normal. ACTH was again gradually withdrawn, this time without difficulty, and the patient was transferred to Eagleville Sanatorium for treatment of tuberculosis on September 3, 1954. A lupus erythematosus cell preparation prior to discharge showed 5 L. E. cells per 100 leukocytes.

During the patient's stay at Eagleville, treatment with streptomycin, isoniazid, $\mathrm{K}$ aminobenzoate and NPH insulin was continued. The insulin was withdrawn during his hospital stay, but the blood sugar level remained normal. The patient improved remarkably and gained 46 pounds. Chest roentgenograms, which on admission to Eagleville showed extensive exudative changes involving the upper aspect of both lungs, now showed clearing of the exudative process with residual fibrosis. However, the sputum still contained acid-fast bacilli. The patient wished to continue his treatment at home, and was discharged as improved on January 14, 1956.

He returned to the special hematology clinic at Temple University Hospital on January 26,1956 . At this time he felt well. The hemoglobin level was $13.5 \mathrm{gm}$ per cent, hematocrit 43 per cent, and leukocyte count 6,300 per cu $\mathrm{mm}$, with a normal differential distribution. An L. E. cell preparation yielded negative results. Anti-tuberculosis medication and Potaba were continued on an ambulatory basis. The patient remained asymptomatic until January 30,1958, when on a routine clinic visit he reported the painless passage of bright red blood in his urine. Following a visit to the urology clinic, he was admitted to the urology service on February 7, 1958, with symptoms of urinary frequency, urgency, dysuria and nocturia. Admission studies indicated the presence of urinary-tract infection due to coliform organisms, apparently on the basis of outlet obstruction.

The hemoglobin level on admission was $13.7 \mathrm{gm}$ per cent, and the leukocyte count 5,500 per cu $\mathrm{mm}$. The level of blood urea nitrogen was $7 \mathrm{mg}$, and total protein $7.8 \mathrm{gm}$ per 100 $\mathrm{ml}$ (albumin $4.7 \mathrm{gm}$, globulin $3.1 \mathrm{gm}$ and an $\mathrm{A} / \mathrm{G}$ ratio of 1.5). The level of fasting blood sugar was $100 \mathrm{mg}$ per $100 \mathrm{ml}$. Serum calcium, phosphorus and alkaline phosphatase levels were normal. A chest roentgenogram showed some fibrosis and contracture in both upper lobes. The patient was given $K$ aminobenzoate (Potaba), streptomycin and isoniazid (Rimifon).

On February 8, 1958, a cystoscopic examination revealed a large vesical calculus and trilobar prostatic hyperplasia. The patient was prepared for surgery by cortisone (150 mg daily) and the calculus was removed suprapubically on February 12. The cortisone dosage was maintained postoperatively. The hemoglobin level on February 19 was 12.5 gm per cent. One week after the initial procedure, the patient was again taken to the operating room and a transurethral resection was performed (spinal anesthesia). Blood loss was minimal and the patient did well until the fourth postoperative day, when the urethral catheter was removed; that evening he suddenly experienced chills and a fever as high as $105^{\circ} \mathrm{F}$. This was attributed to bacteremia associated with removal of the catheter, although culture of a blood specimen taken at the time subsequently yielded no growth. The patient was given chloramphenicol and appeared to be responding well; the fever subsided. The cortisone dosage was gradually reduced to $50 \mathrm{mg}$ daily. On March 3, 1958, he complained of weakness and lightheadedness, and the blood tests were repeated. The hemoglobin level was 5.5 gm per cent, leukocyte count 10,500 per cu $\mathrm{mm}$ with a slight increase in segmented neutrophils, reticulocyte count 1.5 per cent, and thrombocyte count increased. L. E. cell preparations gave negative results. The patient was transfused with packed red blood cells, the cortisone dosage was increased to $75 \mathrm{mg}$ every eight hours, and tetracycline was started. Chloramphenicol was discontinued. A chest x-ray film on March 6, 1958 
revealed prominence of the pulmonary vascular markings and a mottled haziness throughout both lungs. These findings were interpreted as representing either congestion, reactivation of the tuberculous process, or the pulmonary changes of lupus erythematosus. The patient was digitalized on March 6, and appeared to improve symptomatically. On March 7, the hemoglobin level was $10.5 \mathrm{gm}$ per cent, and the reticulocyte count 5.6 per cent. The leukocyte count had risen to $28,200 \mathrm{per} \mathrm{cu} \mathrm{mm}$, with marked neutrophilia. On the evening of March 7, 1958, acute pulmonary edema developed and the patient died.

Necropsy revealed stress ulcers of the gastrointestinal tract and bilateral hemorrhagic, necrotic tracheobronchitis and bronchopneumonia. Culture of these lung tissues demonstrated Staphylococcus aureus, coagulase-positive.

Gross and microscopic observations failed to provide definite evidence of lupus erythematosus activity or of tuberculous infection. Some splenic arterioles showed periarteriolar fibrosis and some of the renal glomeruli showed slight thickening of the basement membrane. Death at age 64 appeared due to overwhelming sepsis.

Comment: Despite the coincidence of widespread tuberculosis and lupus erythematosus, this patient remained in good health for four years while being treated with $\mathrm{K}$ aminobenzoate (Potaba) and anti-tuberculosis drugs. The probable contribution of the previous high dosage of corticosteroids to the development of fulminant tuberculosis in this elderly patient cannot be overlooked.

\section{Case 3}

$C . F$., a 65-year-old white male, was first seen at Temple University Medical Center in October 1958. At that time he gave a history of pain, redness, swelling and stiffness in the small joints of his fingers, toes and feet; this had been present for the preceding four years. Nodules had been noted on his feet, fingers and both forearms. A diagnosis of rheumatoid arthritis had been made, and treatment with $5 \mathrm{mg}$ of prednisone daily had been carried out for a four-year period. Pain relief had been only partial, however. Four months before his visit an eruption developed on the exposed areas of the body, arms, face and neck following exposure to sunlight. It consisted of uniform round, erythematous lesions accompanied by intense itching. Early in August 1958 the patient was seen at the hospital of the National Institutes of Health. Extensive clinical and laboratory studies were made, including an L. E. cell preparation for which the findings were reported as positive. The patient was told that he had lupus erythematosus, and was given prednisone (Meticorten $45 \mathrm{mg}$ daily) for ten weeks.

The past history, family history and system review were non-contributory.

On physical examination the skin of the face, neck, and V-area of the chest was bright red, but no definite lesions were noted. Examination of the extremities revealed a peasized nodule on the dorsal surface of the right lower arm just below the elbow. Similar nodules were also palpable at the bases of the second metatarsophalangeal joints bilaterally. There were no other objective findings in the joints.

On October 29, 1958, the hemoglobin level was $17.1 \mathrm{gm}$ per cent, hematocrit 50 per cent, and leukocyte count 6,400 per cu $\mathrm{mm}$. The level of serum total protein was $6.9 \mathrm{gm}$ per cent (albumin $4.6 \mathrm{gm}$ and globulin $2.3 \mathrm{gm}$ ). An L. E. cell preparation and a cephalin flocculation test gave negative results. The urine was normal.

The patient was given $\mathrm{K}$ aminobenzoate (Potaba, $12 \mathrm{gm}$ daily) and prednisone $(5 \mathrm{mg}$ four times daily). He did well on this regimen, and prednisone had been gradually reduced to $10 \mathrm{mg}$ daily by January 26,1959 . During this time he remained well except for occasional mild joint stiffness. On February $23, \mathrm{~L}$. E. cells were found in the L. E. preparation.

On April 9, 1959, the patient experienced right upper quadrant abdominal pain unrelieved by food, and was admitted to Temple University Medical Center because of possible peptic ulcer. The admission physical examination revealed only right upper quadrant tenderness. Pertinent laboratory findings were: hemoglobin level $14.6 \mathrm{gm}$ per cent, eryth- 
rocyte count $4,500,000$ per cu $\mathrm{mm}$, hematocrit 46 per cent, leukocyte count 6,900 per cu $\mathrm{mm}$ with a normal differential distribution, and platelet count 472,000 per cu $\mathrm{mm}$. An L. E. cell preparation gave negative results. The urine specific gravity was 1.007 , but no other urinary abnormalities were found. The level (per $100 \mathrm{ml}$ ) of blood sugar was 110 $\mathrm{mg}$, blood urea nitrogen $10 \mathrm{mg}$ and total serum protein $5.8 \mathrm{gm}$ (albumin $4.6 \mathrm{gm}$, globulin $1.2 \mathrm{gm}$, and $\mathrm{A} / \mathrm{G}$ ratio 3.8). Results of a cephalin flocculation test were negative. The latex fixation test for rheumatoid arthritis showed a reaction. A gastrointestinal x-ray series revealed a sliding hiatal hernia. An intravenous urogram demonstrated a soft-tissue mass in the right upper quadrant near the lower pole of the right kidney; it measured about 10 cm in diameter.

Exploratory laparotomy was performed on April 30, 1959, and a benign renal cyst (8 $\mathrm{x} 8 \mathrm{~cm}$ ) was excised. The postoperative course was smooth and the patient was discharged on May 9, 1959. His treatment regimen was an ulcer diet, antispasmodics, antacids, and hydrocortisone (10 mg every eight hours). Following discharge he remained well until July 1960 , when there was sudden loss of peripheral vision in the right eye. On examination, a tumor of the retina was discovered, and enucleation was performed shortly thereafter at Wills Eye Hospital. The histologic diagnosis was malignant melanoma.

During the past year the patient has been symptom-free except for occasional stiffness of his muscles and joints. Repeated lupus erythematosus cell preparations have contained 1 or $2 \mathrm{~L}$. E. cells per 500 leukocytes counted. At present, therapy consists of $5 \mathrm{mg}$ daily of prednisone, and $12 \mathrm{gm}$ daily of $\mathrm{K}$ aminobenzoate. The patient is now aged 71 .

Comment: Case 3 also demonstrates the difficulty in attempting to categorize every case of diffuse collagen disease as a single entity. This patient originally exhibited the typical changes of rheumatoid arthritis (involvement of the small joints of the hands and feet, subcutaneous nodules, and positive results with the latex fixation test). Later in his course, a recurrent erythematous eruption and repeatedly positive findings with $\mathrm{L}$. E. cell preparations warranted an additional diagnosis of lupus erythematosus. Since institution of treatment with K aminobenzoate, the patient has been free of troublesome symptoms while taking only $5 \mathrm{mg}$ daily of prednisone.

\section{Case 4}

G. $W$., a 58-year-old male was first admitted to Temple University Hospital on July 16,1950 , with the chief complaint of weakness of two years' duration. In January 1949 he had been studied at another Philadelphia hospital where anemia was observed; treatment with iron, liver, cobalt and $B_{12}$ resulted in little improvement. On April 16, 1950, he was suddenly seized with epigastric pain and was re-admitted to the same hospital where an exploratory laparotomy revealed a distended gall bladder with stones. Cholecystectomy was performed, at which time a normal sized spleen was observed. He was given 6 units of blood. At the time of discharge the diagnosis was "hemolytic anemia."

On admission to 'Temple University Hospital, the patient was fairly well nourished but rather pale. The sclerae were icteric. Abdominal examination revealed the scar of the previous cholecystectomy. The liver was palpable two fingerbreadths below the costal margin in the midclavicular line, and was tender and smooth. The spleen was not palpable. There were typical psoriatic lesions on the buttocks and left knee.

Laboratory findings were as follows: cephalin flocculation, 3+; serum bilirubin (indirect) $1.2 \mathrm{mg}$ per $100 \mathrm{ml}$, serum sodium $150 \mathrm{mEq}$ per liter, serum potassium $4.85 \mathrm{mEq}$ per liter and serum chlorides $378 \mathrm{mg}$ per $100 \mathrm{ml}$. The blood urea nitrogen level was 16 $\mathrm{mg}$ per $100 \mathrm{ml}$. The erythrocyte count was $2,200,000$ per cu mm, hemoglobin level 7.2 gm per cent, hematocrit 21 per cent, reticulocyte count 36 per cent, and leukocyte count 4,400 per cu $\mathrm{mm}$, with $67 \%$ neutrophils, $26 \%$ lymphocytes, $3 \%$ monocytes and $4 \%$ eosin- 
ophils. An osmotic fragility test revealed increased hemolysis in hypotonic saline solutions. Gastric analysis showed mild hyperacidity. The sternal bone marrow aspirate showed marked normoblastic hyperplasia.

A ten-day course of ACTH had no effect, and the patient refused splenectomy. He was discharged on August 9,1950, to be followed in the Medical Clinic, which he visited sporadically. His complaints were chronic fatigue, moderate shortness of breath on exertion, a cough productive of small amounts of phlegm, and occasional bright red blood with bowel movements. Sigmoidoscopy was performed and internal and external hemorrhoids were found. Several chest roentgenograms demonstrated pulmonary fibrosis and emphysema. The liver was palpable two to three fingerbreadths below the costal margin in the midclavicular line, but the spleen was not palpable.

In the period from October 1950 to April 1953, the hemoglobin level remained low, ranging from $7.2 \mathrm{gm}$ to $12.0 \mathrm{gm}$ per cent. The reticulocyte count ranged from 6.4 to 16 per cent. The plasma was consistently icteric. Platelet counts and leukocyte counts were within normal limits. In November 1953 the findings in L. E. cell preparations, which previously had been negative, were positive and remained positive during the ensuing year; as many as $63 \mathrm{~L}$. E. cells per 500 leukocytes were noted in these tests. Coombs' tests gave negative results.

In May 1954, treatment was started with the following: $\mathrm{K}$ aminobenzoate (Potaba, $12 \mathrm{gm}$ per day), cortisone (12.5 mg every eight hours), testosterone Lingusorbs (2.5 $\mathrm{mg}$ per day), and a low-salt regimen. At the time therapy was started, he was complaining of right-sided pleuritic pain, increasing weakness, fatigue and arthralgia. These symptoms were unaccompanied by fever or other objective findings. The hemoglobin level was 12.2 gm per cent, reticulocyte count 2.3 per cent, leukocyte count 6,900 per cu $\mathrm{mm}$, and platelet count 700,000 per cu mm. Therapy was continued for about seven months, with moderate improvement of the subjective complaints. Lupus erythematosus preparations consistently contained L. E. cells.

In January 1955, the patient discontinued treatment against advice. He consulted a non-medical practitioner, who prescribed various herb medications. In November 1955 he returned to clinic after an absence of ten months, with a complaint of pain and progressive limitation of motion in the left shoulder, of two to three months' duration. A roentgenogram of the left shoulder revealed a large destructive lesion involving the glenoid fossa of the left seapula. The patient was admitted to the orthopedic service on November 27,1955 , and a needle biopsy was performed under fluoroscopic guidance. No evidence of tumor was found. A skeletal survey showed no lytic lesions other than that in the left scapula. The level of total serum protein was $6.4 \mathrm{gm}$ per cent (albumin $3.7 \mathrm{gm}$ and globulin $2.7 \mathrm{gm}$ ). The urine was normal. The cells in a sternal marrow aspirate were normal. Smears and cultures of the sputum and the aspirate from the shoulder lesion showed no acid-fast bacilli. During this admission, L. E. cell preparations gave negative results.

The patient was discharged only to be re-admitted to the orthopedic service in January 1956. At that time an open biopsy of the left scapular lesion was performed; the pathology report was adenocarcinoma, probably of a gastrointestinal origin. A chest roentgenogram revealed a destructive lesion of the right sixth rib in the mid-axillary line. A course of local x-ray irradiation (2000 r) was administered to the shoulder, and he was discharged. The patient continued to have marked pain and limitation of motion in the shoulder and was re-admitted in August 1956. The hemoglobin level was $10.2 \mathrm{gm}$ per cent, erythrocyte count 3.5 million per cu mm, hematocrit 32.5 per cent, and leukocyte count 6,500 per cu $\mathrm{mm}$, with normal differential distribution. An L. E. cell preparation gave negative results. The serum levels of acid and alkaline phosphatase and total protein (including A/G ratio) were normal. The urine was normal. The feces contained no occult blood. An intravenous urogram, a gastrointestinal roentgen examination (including barium enema) and bronchoscopy revealed nothing abnormal.

In the absence of a detectable primary lesion, a course of nitrogen mustard therapy was instituted. A dose of $6 \mathrm{mg}$ was given on alternate days until a total dose of $24.0 \mathrm{mg}$ 
was reached. In addition, cortisone (12.5 $\mathrm{mg}$ every eight hours), methyltestosterone sublingually ( $2.5 \mathrm{mg}$ daily), and potassium citrate (1.0 gm three times daily) were administered. This therapy provided little relief and the patient's physical condition continued to deteriorate. He died at home in January 1957. No autopsy was performed.

Comment: This case illustrates the necessity of considering lupus erythematosus as the underlying disease in all cases of acquired hemolytic anemia, regardless of age at onset.

\section{Case 5}

$B . P$., a 74-year-old woman, was first admitted to the hospital on September 26, 1954, with the chief complaint of arthritis of two months' duration. Involved were the metacarpophalangeal joints, the proximal interphalangeal joints and the wrists. She gave a history of a rash on the bridge of her nose, first noted after exposure to sunlight. At the onset of her illness she had been given corticosteroids intravenously and this had afforded temporary relief. When a reduction in dosage was attempted, there was an increase in disability, a fever of 102 to $103^{\circ} \mathrm{F}$, and involvement of additional joints. She was advised to enter the hospital for further evaluation.

On physical examination there were raised, patchy lesions on the skin of the face (thought to resemble discoid lupus), and generalized adenopathy. Both hand grips were weak. There was minimal swelling of the metacarpophalangeal joints and proximal interphalangeal joints, and atrophy of the extensor muscles of the hand.

Laboratory studies: hemoglobin level 12.4 gm per cent, leukocyte count 7,450 per cu $\mathrm{mm}$ with normal differential distribution, and thrombocyte count 271,000 per cu $\mathrm{mm}$. The serologic test for syphilis gave negative results. Urine specific gravity was 1.010 ; $1+$ protein was present and there were 10-12 leukocytes and 18-20 erythrocytes per highpower field. The level of total serum protein was $6.6 \mathrm{gm}$ per cent (albumin $3.5 \mathrm{gm}$ and globulin $3.1 \mathrm{gm}$ ). The blood urea nitrogen level was $11 \mathrm{mg}$ per $100 \mathrm{ml}$. Blood and urine cultures showed no growths. On October 4, 1954, a lupus erythematosus cell preparation contained L. E. cells. A chest x-ray film and an electrocardiogram were within normal limits. Six days following admission the leukocyte count had fallen to 3,000 per $\mathrm{cu} \mathrm{mm}$.

The patient was seen in consultation by one of us (C. Z.), who confirmed the diagnosis of systemic lupus erythematosus. Treatment included a low-salt diet, cortisone (50 $\mathrm{mg}$ every six hours), K aminobenzoate (Potaba, $12 \mathrm{gm}$ daily), and ascorbic acid (50 $\mathrm{mg}$ daily). Within three days her temperature became normal and she improved clinically. She was discharged on the thirty-fifth hospital day and told to take cortisone (50 mg every eight hours) and Potaba (12 gm per day).

The patient did very well during the next two years, being maintained with prednisone (5 mg twice daily) and Potaba (12 gm daily). Her urine showed no evidence of cellular exudation, and joint symptoms were minimal. She regained the 18 pounds in weight which had been lost during her acute illness.

Her second hospital stay was in November 1956, when she was admitted for pain in the lumbar region, aggravated by movement and relieved by lying flat in bed. Laboratory findings: hemoglobin level $12.0 \mathrm{gm}$ per cent, erythrocyte count 3.7 million per cu mm, leukocyte count 6,600 per cu mm with normal differential distribution, and thrombocyte count 422,620 per cu mm. The level of blood urea nitrogen was $18 \mathrm{mg}$ per $100 \mathrm{ml}$, serum phosphorus $4.0 \mathrm{mg}$ per $100 \mathrm{ml}$, and alkaline phosphatase 2.5 units per $100 \mathrm{ml}$. Roentgenograms of the lumbar spine revealed osteoporosis and a compression fracture of L-1. She was fitted with a back brace and discharged. Her medication was prednisone $(5 \mathrm{mg}$ twice daily), norethandrolone (10 $\mathrm{mg}$ four times daily) and stilbestrol (5 mg daily for three weeks out of four). The back pain improved markedly with this program and she remained well.

A year later she entered the hospital for re-evaluation. Roentgen examination showed 
no further progression of the compression fracture of the spine. An abdominal mass was palpated which on pelvic examination was thought to be an ovarian eyst, perhaps stimulated by estrogen administration. The stilbestrol therefore was discontinued but the rest of the regimen was maintained. Again she did well.

In January 1960, she was admitted to the hospital for the fourth and final time. She complained of severe abdominal pain and constipation of three days' duration. On examination, signs of hypercortisonism were evident, i.e., swelling of the soft tissues of the neck and face and truncal obesity. There was abdominal distention with hyperactive peristalsis, generalized tenderness and rebound phenomena. A mass was now palpated in the lower left quadrant, but the previously mentioned right-sided mass was no longer felt. Leukocytes numbered 22,600 per cu mm, with $67 \%$ segmented neutrophils, $15 \%$ nonsegmented forms, $15 \%$ lymphocytes and $3 \%$ monocytes. The hemoglobin level was 16.1 gm per cent. The cephalin flocculation test gave negative results. The serum total protein level was $6.7 \mathrm{gm}$ per cent, with $3.9 \mathrm{gm}$ of albumin.

At laparotomy a perforated sigmoid diverticulum with generalized peritonitis was found. A colostomy was established in the transverse colon. Culture of the peritoneal exudate revealed coliform and proteus organisms. Before, during, and after surgery she was given chloramphenicol. She did well for seven days, but on the eighth postoperative day her temperature rose to $103^{\circ} \mathrm{F}$. Blood cultures showed Gram-negative organisms. Massive doses of antibiotics and corticosteroids failed to reverse a rapidly down-hill course, and she died on January 31, 1960.

Postmortem examination: There was a seropurulent exudate in the abdominal cavity. A large abscess in the sigmoid area communicated with a perforated diverticulum. The adrenals were small and atrophic. The blood vessels of the kidney showed glomerular thickening. There were scattered areas of thickening of the basement membrane with a fibrinoid appearance. These changes were considered compatible with lupus erythematosus.

Comment: This case, in contrast to the others reported here, is quite "typical" of the picture presented by lupus erythematosus in the younger age group -a butterfly rash and arthralgias in a woman.

\section{DISCUSSION}

Analysis of our cases together with a review of the pertinent literature suggests that the pattern of systemic lupus erythematosus as seen in the older population may differ significantly from that seen in most younger persons. Perhaps the most striking observation is the preponderance of males in our group (4 out of 5). This represents a reversal of the usual sex incidence for this disease. Typical series include those of Larson (4) (200 patients, of whom 9 were males) McCombs and Patterson (7) (77 patients, of whom 8 were males) and Rupe and Nickel (5) (100 patients, of whom 34 were males). In only one study other than ours was a majority of males noted. Svanborg and Solvell (10) in Sweden reported a total of 24 patients, of whom 18 were males.

When the age at onset is considered in relation to sex, the statistics are as follows. McCombs and Patterson had 8 patients who manifested signs of systemic lupus erythematosus at age 50 or over; all of these were women. In Rupe and Nickel's series, there were 10 patients with onset at age $50-59$; of these, 5 were males and 5 were females. In the 60-69 year group there were 5 females and 3 males. The only patient in whom systemic lupus erythematosus developed after the age of 70 was a male. Svanborg and Solvell's 24 patients (with the previously 
mentioned male preponderance) included 8 who were first noted to have the disease after age 53 ; all of these were men. In contrast, Harvey et al. (1) noted no difference in the age at onset between males and females.

Although no conclusions can be drawn from these conflicting data (Table 1), it appears that males constitute a somewhat larger percentage of the patients who first manifest lupus erythematosus after the age of 50 .

The relationship of the virulence of the disease process to the age at onset has been discussed by McCombs and Patterson, in whose series the appearance of systemic lupus erythematosus after age 45 indicated a more favorable prognosis than when the onset was earlier in life. In a panel discussion published in "Inflammation and Diseases of Connective Tissue" (Hahnemann Symposium) (11), Dubois also states that the disease is apparently more malignant in the younger patient and more benign in the older one. Of our 5 patients, 1 is alive and clinically well five years after the diagnosis of systemic lupus erythematosus was established; 2 died from carcinoma (one at age 80 after seven years of comfortable active life, and the other at age 65 , eight years after symptoms attributable to lupus were first noted); and 2 died of infections intimately related to surgical conditions, five and six years respectively after diagnosis of systemic lupus. It is of interest that all of our cases survived at least five years following definitive diagnosis, and that the 4 deaths were not directly related to the primary disease nor, apparently, to complications secondary to its treatment.

The discovery of a malignant neoplasm either before death or at necropsy in 3 of our 5 patients is noteworthy. In the 183 cases reviewed by Harvey (1), fulminating infection was the cause of death in all patients in whom manifestations of systemic lupus erythematosus were not believed to be directly responsible. There were no carcinomas reported in 91 deaths in Larson's (4) series nor in the smaller groups of Jessar et al. (3), and McCombs and Patterson. Lansbury (12) reported 6 cases of collagen disease complicating malignant disease. In 2 of these patients -one a 36-year-old man with a seminoma, and the other a 57-year old man with squamous-cell carcinoma of the epiglottis and larynx-articular disturbances developed, in association with L. E. cells in lupus erythematosus cell

TABLE 1

Data from the Literature re Age at Onset in Relation to Sex

\begin{tabular}{|c|c|c|c|}
\hline & $\underset{\text { Patterson }}{\text { McCombs \& }}$ & Rupe \& Nickel & Svanborg \& Solvell \\
\hline Total number of cases.... & 77 & 100 & 24 \\
\hline Total number of males........... & 8 & 34 & 18 \\
\hline \multicolumn{4}{|l|}{ Number with onset after age 50 : } \\
\hline Males. . . . . . . . . . . . . . . . . & 0 & 9 & 8 \\
\hline 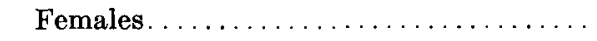 & 8 & 10 & 0 \\
\hline \multicolumn{4}{|l|}{$\begin{array}{l}\text { Percentage of total with onset after } \\
\text { age 50: }\end{array}$} \\
\hline 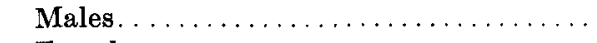 & 0 & 23 & 44 \\
\hline Females. . . . . . . . . . . . . . . & 19 & 12 & $\mathbf{0}$ \\
\hline
\end{tabular}


preparations, within a year after the onset of the symptoms of malignancy. In our 3 cases, the collagen disease was evident for several years before the discovery of the tumors.

The paucity of previously published cases of co-existing malignant neoplasia and systemic lupus erythematosus is in direct contrast to the plethora of reports emphasizing the co-existence of a closely related collagen disease, dermatomyositis, and visceral malignant neoplasia. Lansbury (12), Curtis et al. (13), Sheard (14), and Brunner and Lobraccio (15) all reported 1 or more cases prior to 1954. At present, it is thought that from 10 to 20 per cent of patients with dermatomyositis have, or will have, a malignant neoplasm.

Scleroderma, a third member of the collagen-disease group, although not widely recognized as associated with an increased incidence of malignant disease, has been reported as co-existing with pulmonary carcinoma by several observers (16-18). Another case of pulmonary carcinoma complicating longstanding scleroderma has been followed personally by the authors, as has a case of careinoma of the sigmoid colon developing in a patient with scleroderma of many years' duration.

Although it is not possible to relate any causal significance to the occurrence of malignant disease in our small series, it seems warranted to advise that search for an occult tumor be made in any patient in whom the clinical onset of lupus erythematosus has occurred in the later years of life.

The phenomenon of demonstrable protein abnormalities preceding the earliest symptoms of lupus erythematosus by many years is well documented. Harvey (19) studied 192 patients in whom biologic tests for syphilis gave false-positive results; in 14 of these, systemic lupus developed. Haserick and Long (20) reviewed the courses of 5 patients whose false-positive serologic reactions for for syphilis antedated the appearance of clinical lupus erythematosus by one to seven years. Moore and Lutz (21) reported 9 cases of verified systemic lupus that developed in 104 female biologic false-positive reactors from five to fifteen years after the abnormal serologic findings were first obtained. In addition, 52 of their patients eventually exhibited bizarre illnesses having features consistent with a collagen disease, but without lupus erythematosus cells in the L. E. cell preparations. In our Case 1, there was a 40 -year history of positive reactions in the serologic tests for syphilis; these were proved to be biologic false-positive reactions, on the basis of repeatedly negative results with Treponema pallidum immobilization tests. Although elevated levels of spinal fluid protein have frequently been found in patients with neurologic manifestations of systemic lupus, a search of the literature has failed to disclose any reports previous to that in our Case 1 of a false-positive cerebrospinal fluid reaction for syphilis in a case of lupus erythematosus.

In another patient (not reported here in detail) in whom the diagnosis of lupus was made at age 53, there was a history of "sun poisoning" and a rash suggestive of a butterfly eruption twenty-five years before the onset of intermittent fever and arthralgias associated with L. E. cells in lupus erythematosus cell preparations. This woman also reported hypersensitivity reactions to penicillin and 
transfusions during the period between the probable origin of her disease and the emergence of a typical clinical and laboratory pattern. This case and Case 1 contribute further evidence to support the existence of a "lupus diathesis," in which isolated clinical or laboratory signs, or both, of the disease may precede the full blown syndrome by many years. In our series (with the possible exception of Case 1) we could not determine at what age some abnormality related to lupus may have first been detectable. One can only speculate that in cases of systemic lupus apparently arising late in life, the evolution of the disease has been slow, and that subclinical abnormalities have existed for long periods. Careful retrospective studies of the past histories and laboratory records of elderly patients with lupus erythematosus, as well as follow-up evaluations of serologic falsepositive reactors and other patients with the "lupus diathesis," are indispensable for confirmation of this hypothesis.

The use of both $\mathrm{K}$ aminobenzoate and corticosteroids in the long-term management of systemic lupus erythematosus deserves comment. $K$ aminobenzoate (Potaba) was first used successfully in the treatment of chronic discoid lupus by one of us in the 1940's (22, 23). Early trials in systemic lupus, however, showed that only occasional patients with the disseminated form of the disease would respond to this medication. Accordingly, $\mathrm{K}$ aminobenzoate was not suggested as a primary form of treatment for the systemic form of the disease. Later, however, it was determined that by the introduction of this compound (at least $12 \mathrm{gm}$ daily) into the treatment program, the amount of corticosteroids required for suppression of the clinical manifestations of systemic lupus, as well as of other disorders, could be substantially reduced $(24,25)$. The desirability of minimizing long-term steroid dosage in all patients is well recognized. In the elderly patient, already prone to demineralization, the lessened risk of this complication occurring if $\mathrm{K}$ aminobenzoate is added to therapy, is a particular advantage. The longterm use of $\mathbf{K}$ aminobenzoate in conjunction with small doses of corticosteroids resulted in prolonged, relatively symptom-free periods in 4 patients of this series.

\section{SUMMARY}

Five cases of systemic lupus erythematosus with apparent onset in the sixth decade of life or later are presented. Striking features of this series included the predominance of males ( 4 out of 5 ), the co-existence or development of malignant tumors in 3 of the 5 cases, and the fact that none of the 4 deaths was the direct result of systemic lupus or apparent complications of its treatment, which consisted chiefly of potassium para-aminobenzoate and small doses of corticosteroids. A unique finding was that in 1 case a positive reaction with the serologic test for syphilis on the cerebrospinal fluid proved to be a biologic false-positive reaction.

In elderly patients, systemic lupus erythematosus should be considered in the differential diagnosis when any clinical or laboratory phenomena are observed which would arouse suspicion of this disorder in younger patients.

\section{Acknowledgment}

The authors wish to thank Dr. H. James Day for permission to include Cases 3 and 5 . 


\section{REFERENCES}

1. Harvey, A. M.; Shulman, L. E.; Tumulty, P. A.; Conley, C. L., and Schoenrich, E. H.: Systemic lupus erythematosus : review of the literature and clinical analysis of 138 cases, Medicine 33: 291 (Dec.) 1954.

2. Shearn, M. A., And Perofsky, B.: Disseminated lupus erythematosus: analysis of 34 cases, Arch. Int. Med. 90: 790 (Dec.) 1952.

3. Jessar, R. A.; Lamont-Havers, R. W., and Ragan, C.: Natural history of lupus erythematosus disseminatus, Ann. Int. Med. 38: 717 (Apr.) 1953.

4. Larson, D. L.: Systemic Lupus Erythematosus. Boston, Mass., Little, Brown and Co., 1953.

5. Talbott, N. H., and Ferrandis, R. M.: Collagen Diseases. New York, Grune and Stratton, 1956.

6. Rupe, C. E., ANd Nickel, S. N.: New clinical concept of systemic lupus erythematosus: analysis of 100 cases, J.A.M.A. 171: 1055 (Oct. 24) 1959.

7. McCombs, R. P., and Patterson, J. F.: Factors influencing course and prognosis of systemic lupus erythematosus, New England J. Med. 260: 1955 (June 11) 1959.

8. Haserick, J. R.: Modern concept of systemic lupus erythematosus: review of 126 cases, J. Chronic Dis. 1: 317 (March) 1955.

9. Knopf, R. F., and Castor, C. W.: Systemic lupus erythematosus in an elderly patient: a case report, Univ. of Mich. Med. Bull. 25: 20 (Jan.) 1959.

10. Svanborg, A., And Solvell, L.: Incidence of disseminated Iupus erythematosus: follow-up studies indicating increased frequency, J.A.M.A. 165: 1126 (Nov. 2) 1957.

11. Dubois, E. L.: In Inflammation and Diseases of Connective Tissues, ed. by L. C. Mills and J. H. Moyer. Philadelphia and London, W. B. Saunders Co., 1961.

12. Lansburr, J.: Collagen disease complicating malignancy, Ann. Rheum. Dis. 12: 301 (Dec.) 1953.

13. Clrtis, A. C.; Blaylock, H. C., and Harrell, E. R., Jr.: Malignant lesions associated with dermatomyositis, J.A.M.A. 150: 844 (Nov. 1) 1952.

14. Sheard, C., Jr.: Dermatomyositis, Arch. Int. Med. 88: 640 (Nov.) 1951.

15. Brunner, M. J., And Lobraccio, R. V., JR.: Dermatomyositis as an index of malignant neoplasm, Ann. Int. Med. 34: 1269 (May) 1951.

16. Richards, R. L., and Mrlne, J. A. : Cancer of the lung in progressive systemic sclerosis, Thorax 13: 238 (Sept.) 1958.

17. Zatuchin, J.; Campbell, W. N., and Zarafonetis, C. J. D.: Pulmonary fibrosis and terminal bronchiolar (alveolar cell) carcinoma in scleroderma, Cancer 6: 1147 (Nov.) 1953.

18. Jonsson, S. M., AND Houser, J. M.: Scleroderma (progressive systemic sclerosis) associated with cancer of the lung, New England J. Med. 255: 413 (Aug. 30) 1956.

19. Harvey, A. M.: Auto-immune disease and the chronic biologic false-positive test for syphilis, J.A.M.A. 182: 5 (Nov. 3) 1962.

20. Haserick, J. R., ANd Lowg, R.: Systemic lupus erythematosus preceded by false-positive serological tests for syphilis : presentation of 5 cases, Ann. Int. Med. 37: 559 (Sept.) 1952.

21. Moore, J. E., AND Lutz, W. B.: The natural history of systemic lupus erythematosus: an approach to its study through chronic biologic false-positive reactors, $J$. Chronic Dis. 1: 297 (March) 1955.

22. Zarafonetis, C. J. D.; Grekin, R. H., and Curtis, A. C.: Further studies on the treatment of Iupus erythematosus with sodium para-aminobenzoate, J. Invest. Derm. 11: 359 (Nov.) 1948.

23. Zarafonetis, C. J. D.: Therapeutic possibilities of para-aminobenzoic acid, Ann. Int. Med. 30: 1188 (June) 1949.

24. Zarafonetis, C. J. D.; Curtis, A. C., and Shaw, J. M.: Treatment of pemphigus with potassium para-aminobenzoate, Am. J. M. Sc. 231: 30 (Jan.) 1956.

25. Zarafonetis, C. J. D.: Lupus erythematosus and other collagen diseases. Presented at Meeting of The Michigan Academy of Practice (Symposium on Inflammation), Detroit, Mich., March 1, 1961. 